\title{
Giant Bilateral Renal Angiomyolipomas and Lymphangioleiomyomatosis Presenting after Two Successive Pregnancies Successfully Treated with Surgery and Rapamycin
}

\author{
Ramón Peces, ${ }^{1}$ Emilio Cuesta-López, ${ }^{2}$ Carlos Peces, ${ }^{3}$ and Rafael Selgas ${ }^{1}$ \\ ${ }^{1}$ Servicio de Nefrología, Hospital Universitario La Paz, IdiPAZ, 28046 Madrid, Spain \\ ${ }^{2}$ Servicio de Radiología, Hospital Universitario La Paz, 28046 Madrid, Spain \\ ${ }^{3}$ Area de Tecnología de la Información, SESCAM, 45071 Toledo, Spain
}

Received 15 July 2011; Accepted 4 October 2011

Academic Editor: Daniel Batlle

We report the case of a 25 -year-old woman who presented with abdominal and flank pain with two successive pregnancies and was diagnosed of giant bilateral renal AMLs and pulmonary LAM associated with TSC in the post-partum of her second pregnancy. This case illustrates that in women with TSC rapid growth from renal AMLs and development of LAM may occur with successive pregnancies. It also stresses the potential for preservation of renal function despite successive bilateral renal surgery of giant AMLs. Moreover, the treatment with a low-dose rapamycin may be an option for LAM treatment. Finally, a low-dose rapamycin may be considered as an adjuvant treatment together to kidney-sparing conservative surgery for renal AMLs.

KEYWORDS: Angiomyolipomas, lymphangioleiomyomatosis, nephrectomy, mTOR, pregnancy, tuberous sclerosis complex 


\section{INTRODUCTION}

Tuberous sclerosis complex (TSC), a rare autosomal dominant disorder with variable penetrance, affects approximately 1 in 10.000 people [1]. TSC is caused by mutations of TSC1 or TSC2 genes. Products of these genes, hamartin and tuberin, create a complex that inhibits mTOR, a key protein engaged in regulation of the cell cycle. Mutations of TSC genes lead to constitutive activation of mTOR resulting in uncontrolled proliferation, differentiation, and migration of cells. TSC is a multi-system disease characterized by the presence of benign tumours in many tissues, mostly localized in skin, brain, kidney, and lungs [1]. Renal angiomyolipomas (AMLs) are benign but progressive tumours consisting of smooth muscle, fat, and vascular elements, that are commonly associated with the TSC. AMLs express estrogen and progesterone receptors and have been reported to increase in size during pregnancy [2-10]. Serious maternal complications include abdominal pain, acute intra-abdominal bleeding due to a ruptured renal tumour, and severe preeclampsia, with pathologically enlarged kidneys noted at the time of Caesarean section $[2-6,9,10]$. Pulmonary lymphangioleiomyomatosis (LAM) is a common disease of young women with TSC, which affects the lungs and lymphatics. Clinical symptoms include shortness of breath with exertion, pneumothorax, and fatigue, leading to debilitating respiratory impairment in many cases [11-14]. Since LAM almost exclusively affects women and can be exacerbated by exogenous estrogens [15], it has been assumed that estrogens are associated with disease progression and that increased estrogen levels during pregnancy may originate or exacerbate the disease [13-15].

The management of AMLs during pregnancy usually is to leave the mass alone if it is asymptomatic or to remove it if by virtue of size or other complications like hemorrhage when it is symptomatic [16]. The surgical management of renal AMLs fundamentally aims to preserve the healthy kidney tissue, particularly in the case of large, multiple, bilateral, or recurrent tumours. Among the management options that preserve kidney function, selective arterial embolization, tumour resection, and partial nephrectomy are the most widely used approaches $[6,16]$. Although kidney-sparing conservative surgery and interventional radiological techniques have largely supplanted nephrectomy for the management of problematic AMLs, there is a clear need for less invasive therapies. In LAM, hormonal therapy (i.e., estrogen antagonists) has been tried but without consistent success. The involvement of mTOR in AMLs and LAM pathogenesis is the basis for therapeutic trials of mTOR inhibitors that have demonstrated positive results after rapamycin $[17,18]$. The problems that could arise from renal AMLs associated with LAM during successive pregnancies have not been reported in the literature [19-21]. For this reason, we report the exceptional case of a woman who presented with abdominal and flank pain in two successive pregnancies, and who was diagnosed of giant bilateral renal AMLs together with the presence of LAM in the postpartum of her second pregnancy. After embolization and resection of one kidney, and nephron-sparing conservative surgery of the other, the patient was treated with low-dose rapamycin for 12 months.

\section{CASE REPORT}

A 25-year-old woman without surgical antecedents of interest became pregnant for the first time in September 2005. In December 2005, she visited an emergency room of a hospital complaining of pain at the left flank. Physical examination and laboratory test findings were within normal limits, and management was limited to observation. The pregnancy was complicated by preeclampsia and was terminated successfully at week 38, by means of a Caesarean section in June 2006, giving birth to a male baby who weighed $3070 \mathrm{~g}$. On August 2006, she visited the emergency room of another hospital complaining of abdominal pain localized at the left flank. Since the patient was hemodynamically stable, with physical examination and laboratory test findings within normal limits, management was limited to observation with the patient remaining stable, without lumbar pain, hematuria or other urological symptoms. In May 2008, the patient became pregnant for the second time. At the 14th week of gestation, she presented with metrorrhagia, and management was limited to absolute rest. During the second and third trimesters of her pregnancy, she presented mild 


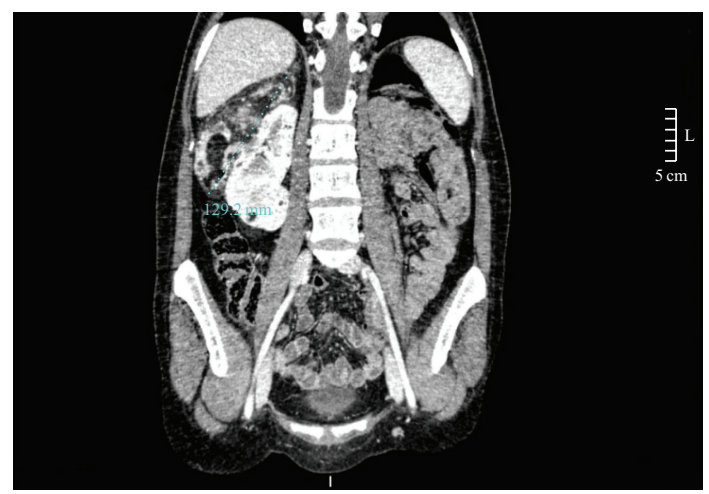

(a)

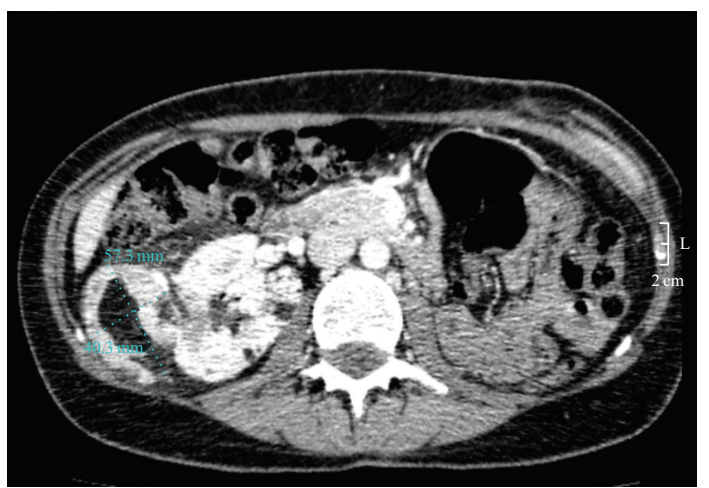

(b)

FIGURE 1: (a) Coronal CT revealing a well-circumscribed heterogenic mass lateral to the right kidney with appearance of a giant angiomyolipoma measuring $129.2 \times 51.5 \mathrm{~mm}$. (b) Axial CT appearance of the right renal angiomyolipoma measuring $57.3 \times 40.3 \mathrm{~mm}$. Small intraparenchymatous cystic lesions were present.

abdominal and left flank pain and was treated for a urinary tract infection. At the 38th week of gestation, she underwent elective Caesarean section. A female baby weighing $2990 \mathrm{~g}$ was delivered. In March 2009, postdelivery abdominal computed tomography (CT) showed the presence of bilateral renal AMLs, with a mass in the upper pole of the right kidney, measuring $70 \times 80 \mathrm{~mm}$ in size, together with another mass in the middle-third portion of the left kidney, measuring $140 \times 140 \times 110 \mathrm{~mm}$ in size, and a smaller similar lesion of $60 \times 40 \mathrm{~mm}$ in the upper pole, without evidence of recent bleeding. In May 2009, two months postpartum, she underwent embolization of renal AMLs and left nephrectomy. At surgery, because the masses had become very extensive and a partial left nephrectomy was considered impossible, the patient underwent a radical left nephrectomy. Additionally, tubaric ligation was performed. The histological study of the resected masses and kidney revealed the presence of lesions compatible with the diagnosis of renal AMLs.

In September 2009, the patient was transferred to our hospital for further evaluation, and she denied any family history of TSC. She had mild nonprogressive exertional dyspnea with some limitation of daily activities initiated after delivery. Physical examination revealed subungual fibromas, facial angiofibromas, hypomelanotic macules, and shagreen patches. There was a tender mass in her right hemiabdomen. At that time, serum creatinine was $0.8 \mathrm{mg} / \mathrm{dL}(70.72 \mu \mathrm{mol} / \mathrm{L})$. In November 2009 , an abdominal magnetic resonance image (MRI) and a CT showed an increase in the size of the right renal AML within 8 months, measuring $129.2 \times 57.3 \times 40.3 \mathrm{~mm}$, and characteristic areas representing fat, without evidence of recent bleeding. Several small intraparenchymatous cystic lesions less than $14 \mathrm{~mm}$ were present (Figure 1). Helical chest CT showed innumerable thin-walled cystic air spaces of different sizes throughout the lung parenchyma, characteristic of pulmonary LAM (Figure 2(a)). Complete pulmonary-function testing including the measurement of spirometric variables, lung volumes, and diffusing capacity demonstrated mild airflow obstruction, moderate air trapping, and normal gas exchange (Table 1). CT and MRI of brain did not reveal features suggestive of tuberous sclerosis. Ophthalmological examination did not suggest retinal hamartomas. Transthoracic echocardiogram did not reveal cardiac rhabdomyomas. In January 2010, the patient underwent right lumbotomy with resection and enucleation of the tumours of the right kidney, preserving the renal tissue as much as possible. In order to minimize the risk of pneumothorax due to barotraumas, the ventilatory settings were adjusted. She had a full and uneventful recovery with stable renal function. The lateral renal tumour sized $140 \times 90 \times 40 \mathrm{~mm}$ (weight $233 \mathrm{~g}$ ) and the tumour of the inferior pole sized $35 \times 25 \mathrm{~mm}$. The histological study of the resected masses was compatible with the diagnosis of renal AMLs. An MRI performed two months later revealed a right kidney well preserved with only small intraparenchymatous AMLs (Figure 3). At that time, the serum creatinine was $0.7 \mathrm{mg} / \mathrm{dL}(61.88 \mu \mathrm{mol} / \mathrm{L})$. 


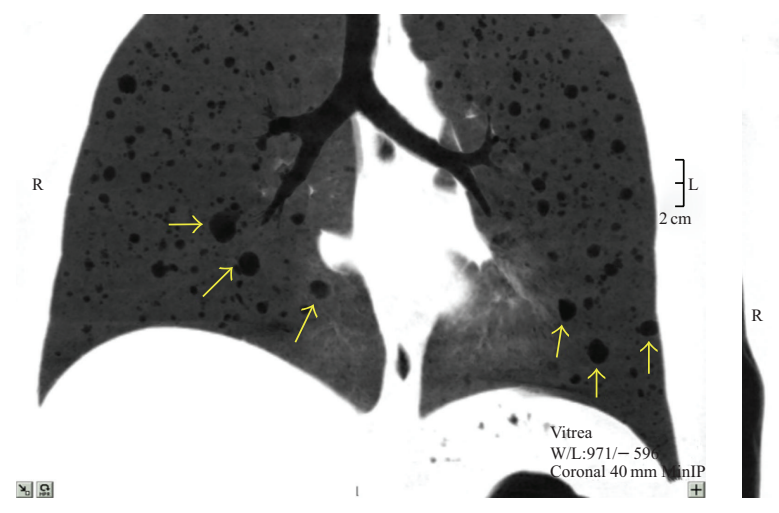

(a)

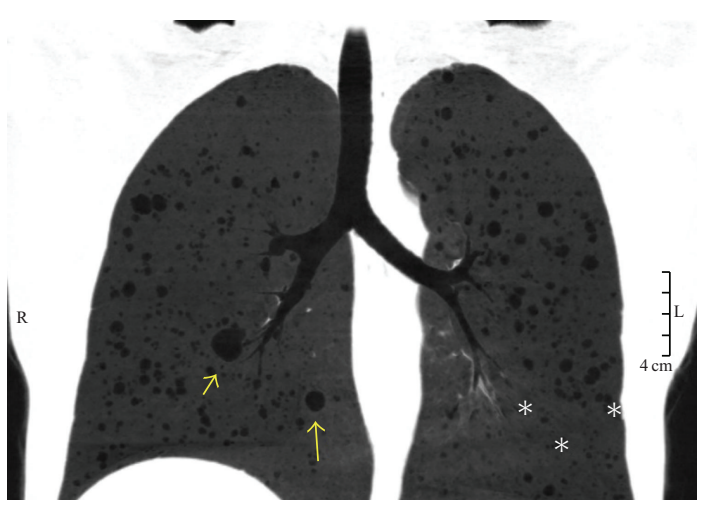

(b)

FIGURE 2: (a) Coronal CT revealing pulmonary lymphangioleiomyomatosis with a moderate degree of pulmonary cystic affectation. Three lesions in each lung are identified by arrows. (b) Coronal CT revealing a marked resolution of pulmonary cysts after a 6-month treatment with low-dose rapamycin. One lesion in the right lung and three in the left had become imperceptible (arrows and asterisks).

Because of clinical trials demonstrating efficacy of rapamycin in LAM, our patient was started on low-dose rapamycin ( $1 \mathrm{mg} /$ day), aiming for trough levels of $2.5-4 \mathrm{ng} / \mathrm{mL}$, in March of 2010. Informed consent for off-label therapy (compassionate use) with rapamycin was obtained. Renal function, proteinuria, lipid profile, blood rapamycin levels, and pulmonary function were monitored throughout the treatment phase. CT of the lungs was performed during full inspiration and during full expiration, with the use of thin-section images. Six and 12 months after the initiation of rapamycin therapy, the patient had a steady improvement in exercise capacity, with an improvement of her pulmonary function: increase in forced expiratory volume in 1 second $\left(\mathrm{FEV}_{1}\right)$, increase in forced vital capacity (FVC), increase in total lung capacity (TLC), and reduction in residual volume (RV) and RV/TLC (\%). There were no changes in diffusing capacity of the lung for carbon monoxide ( $\mathrm{DL}_{\mathrm{CO}}$ ) (Table 1). A thoracic-abdominal CT showed radiological improvement in the LAM lesions 6 months after the initiation of rapamycin therapy (Figure 2(b)). After 12 months, the right kidney remained well preserved with only small intraparenchymatous AMLs (Figure 4). The serum creatinine was $0.7 \mathrm{mg} / \mathrm{dL}(61.88 \mu \mathrm{mol} / \mathrm{L})$, and urine protein did not change (Table 2). Except for initial oral ulcers and hypercholesterolemia, the treatment with rapamycin was well tolerated. Her treatment with low-dose rapamycin and fluvastatin is continuing.

\section{DISCUSSION}

Renal AMLs associated with TSC are uncommon during pregnancy. The most common signs and symptoms are abdominal pain, a palpable abdominal mass, hematuria, and other consequences of intratumoral hemorrhage. The symptoms and complications of AMLs are related to their size and rapidity of growth. Furthermore, the size of renal AMLs would appear to increase dramatically during pregnancy $[2-6,9,10]$. These data, along with the known female predominance of these lesions and reports of AMLs growth in patients with increased circulating hormone levels, suggest a possible role for sex steroids in the pathogenesis of renal AMLs [8]. Since there are few papers available in the literature, there is not an agreement about therapeutic management when pregnant women present with increased growth of AMLs $[6,10,11]$. Treatment options include partial or total nephrectomy (with Cesarean section simultaneously in patients at 28 weeks of gestation or later), tumour resection, selective arterial embolization (which can also be preventive), and sometimes conservative management. There is still disagreement about the risk of vaginal delivery compared with that of Caesarean section, in terms of bleeding of the AMLs $[6,10,11]$. 
TABLE 1: Effect of rapamycin on pulmonary function in a patient with LAM treated for 12 months.

\begin{tabular}{|c|c|c|c|c|}
\hline Variable & $\begin{array}{c}-5 \text { months } \\
\text { (November 2009) }\end{array}$ & $\begin{array}{c}\text { Baseline } \\
\text { (March 2010) }\end{array}$ & $\begin{array}{c}\text { +6 months } \\
\text { rapamycin } \\
\text { (October 2010) }\end{array}$ & $\begin{array}{l}+12 \text { months } \\
\text { rapamycin } \\
\text { (April 2011) }\end{array}$ \\
\hline \multicolumn{5}{|l|}{$\mathrm{FEV}_{1}$} \\
\hline Volume (mL) & 2920 & 2810 & 3140 & 3080 \\
\hline$\%$ of predicted value & 83.5 & 80.9 & 90.5 & 89.5 \\
\hline \multicolumn{5}{|l|}{ FVC } \\
\hline Volume (mL) & 3870 & 3440 & 3810 & 4010 \\
\hline$\%$ of predicted value & 96.7 & 86.5 & 95.8 & 101.4 \\
\hline $\mathrm{FEV}_{1} / \mathrm{FVC}(\%)$ & 75.4 & 81.6 & 82.4 & 77.0 \\
\hline TLC (mL) & 5140 & 5380 & 5530 & 6110 \\
\hline$\%$ of predicted value & 92.4 & 96.7 & 99.5 & 109.9 \\
\hline $\mathrm{RV}(\mathrm{mL})$ & 2120 & 2490 & 1860 & 2140 \\
\hline$\%$ of predicted value & 135.7 & 157.7 & 117.6 & 134.6 \\
\hline RV/TLC (\%) & $41.24(144.8 \%)$ & $46.24(160.4 \%)$ & $33.53(116.4 \%)$ & $35.08(120.3 \%)$ \\
\hline \multicolumn{5}{|l|}{$\mathrm{DL}_{\mathrm{CO}}$} \\
\hline $\begin{array}{l}\text { Diffusing capacity } \\
\text { (mL/mm Hg/min) }\end{array}$ & 8.46 & 9.19 & 8.84 & 8.52 \\
\hline$\%$ of predicted value & 85.0 & 92.7 & 89.2 & 86.4 \\
\hline $\mathrm{DL}_{\mathrm{CO}} / \mathrm{VA}(\%)$ & $2.00(111.8 \%)$ & $2.21(124.2 \%)$ & $1.66(93.3 \%)$ & $1.61(90.7 \%)$ \\
\hline
\end{tabular}

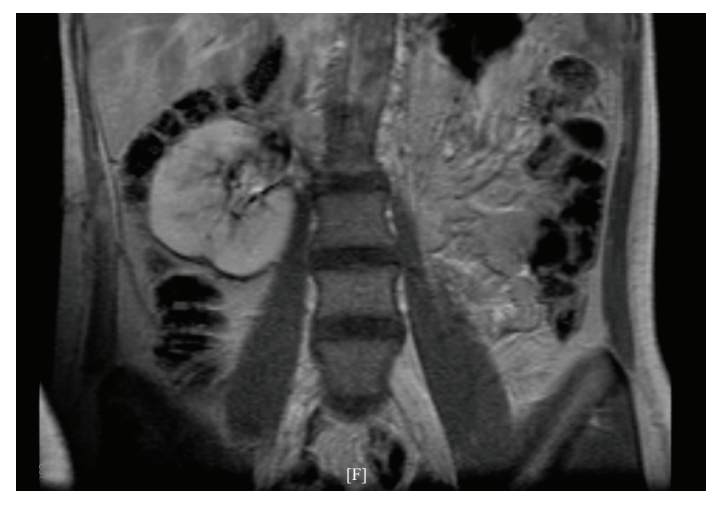

(a)

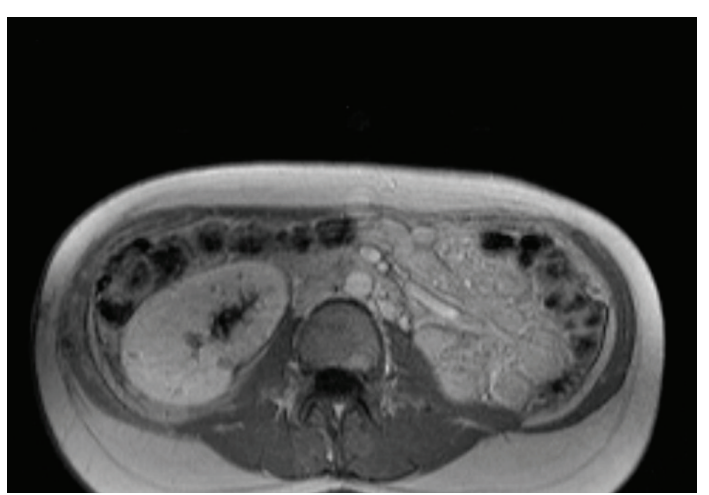

(b)

FIGURE 3: MRI showing the right kidney 2 months after kidney-sparing conservative surgery. (a) Coronal appearance of the right kidney. (b) Axial appearance of the right kidney. Good kidney preservation was apparent. 


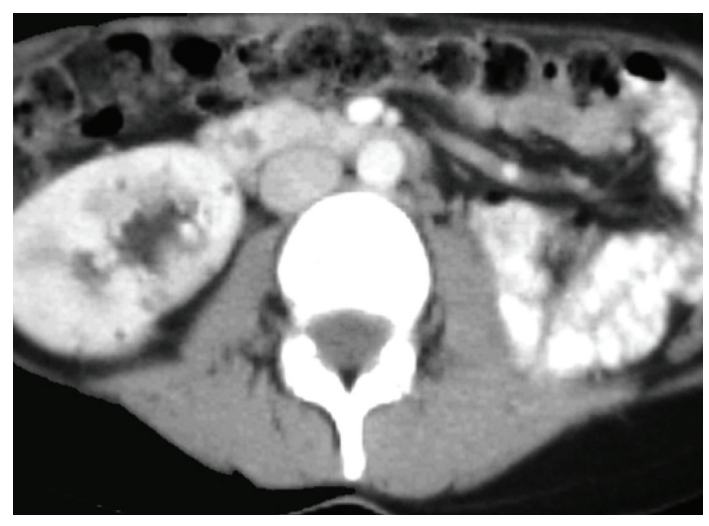

(a)

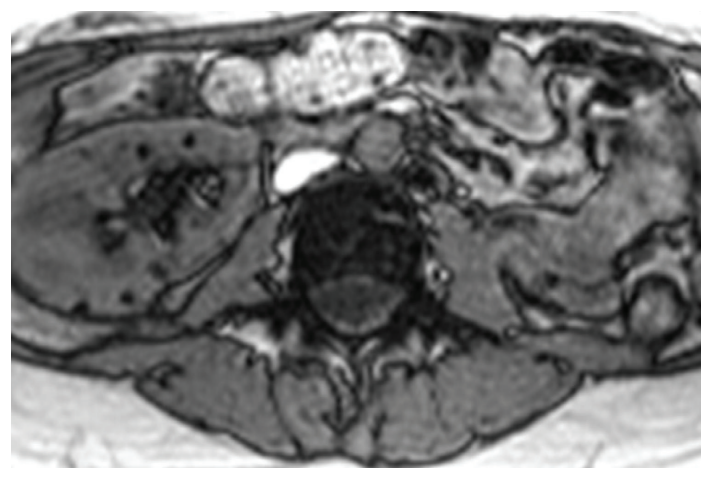

(b)

FIGURE 4: (a) Axial CT appearance of the right kidney after a 12-month treatment with low-dose rapamycin. (b) Axial MRI appearance of the right kidney after a 12-month treatment with low-dose rapamycin. No angiomyolipomas regrowth was apparent. Only small intraparenchymatous cystic lesions less than $14 \mathrm{~mm}$ were present.

While it has been known that AMLs have a tendency to bleed during pregnancy, rarely has it been reported that if the lesion is not treated between pregnancies, the risk of rapid growth increases with successive pregnancies $[6,10]$ as our case clearly demonstrated.

Pulmonary LAM, that may occur in isolation or as a TSC associated condition, is a rare progressive disease that predominantly affects women of child-bearing age, characterized by cystic lung destruction. Estrogen is thought to play a role in disease progression since it does not present prior to menarche and only rarely after menopause and is exceptional in men [19, 20]. LAM is associated with a very unusual disease mechanism: the metastasis of histologically benign TSC1 or TSC2-null cells. LAM has one of the strongest gender predispositions of any extragenital human disease, with a higher female-to-male ratio than even breast cancer. Estrogen receptor alpha is expressed in LAM cells and in AML cells from LAM patients, and estrogen has been shown to activate p42/44 MAPK and stimulate the proliferation of Tsc2-null ELT3 cells and TSC2-null AML cells [22]. Furthermore, a number of case reports have described LAM presenting or worsening during pregnancy [13-15, 20,21]. The disease has a progressive pattern resulting in increasing airflow obstruction and impairment of gas transfer although clinical progression and rate of decline of lung function vary markedly between patients. While there is significant interest in the use of rapamycin in LAM, most patients currently receive supportive care including bronchodilators, supplemental oxygen, and lung transplantation as a last resort [12].

This paper describes the coincidental occurrence of giant bilateral renal AMLs and LAM associated with TSC in a patient with two successive pregnancies. Our patient had two uneventful pregnancies, without any episodes of retroperitoneal bleeding, and both pregnancies ended successfully by means of a Caesarean section. This patient presented with abdominal pain and preeclampsia during her first pregnancy, but surveillance without complications was possible until reaching 38 weeks of gestation. After delivery, renal AMLs remained undiagnosed. Two years later, the patient became pregnant for the second time. She presented with abdominal pain during her second pregnancy, but the presence of bilateral renal masses could not be established until the postpartum period. At that time, bilateral giant renal AMLs were detected, leading to embolization and radical left nephrectomy to avoid the risk of spontaneous rupture. Afterwards, AMLs of the right kidney increased dramatically in size after delivery (a $59.2 \mathrm{~mm}$ increase in diameter within 8 months). There was no active hemorrhage, but due to the size of AMLs, a resection and enucleation of the tumours of the right kidney was performed. In an attempt to avoid unilateral nephrectomy, the patient 
TABLE 2: Laboratory values of a TSC patient with LAM treated for 12 months with rapamycin.

\begin{tabular}{lccccc}
\hline Date & $\begin{array}{c}\text { Cr mg/dL } \\
(\mu \mathrm{mol} / \mathrm{L})\end{array}$ & $\begin{array}{c}\text { Cystatin C } \\
\mathrm{mg} / \mathrm{L}\end{array}$ & $\begin{array}{c}\text { Prot/Cr } \\
(\text { urine })\end{array}$ & $\begin{array}{c}\text { Rapamycin dose } \\
\mathrm{mg} / \mathrm{day}\end{array}$ & $\begin{array}{c}\text { Rapamycin } \\
\text { levels } \\
\mathrm{ng} / \mathrm{mL}\end{array}$ \\
\hline February 12, 2010 & $0.7(61.88)$ & 1.02 & 0.20 & - & - \\
April 5, 2010 & - & - & - & 1 & 2.87 \\
May 5, 2010 & $0.8(70.72)$ & 0.86 & 0.11 & 1 & 2.84 \\
June 21, 2010 & $0.8(70.72)$ & 0.95 & 0.29 & 1 & 3.95 \\
September 28, 2010 & $0.9(79.56)$ & 0.84 & 0.16 & 1 & 3.56 \\
January 17, 2011 & $0.8(70.72)$ & 0.90 & 0.19 & 1 & 3.30 \\
April 7, 2011 & $0.7(61.88)$ & 0.89 & 0.13 & 1 & 2.85 \\
\hline
\end{tabular}

was treated with kidney-sparing conservative surgery of her right kidney. Thus, removal of the unique remnant kidney was prevented, and initiation of dialysis was avoided.

In our patient, the presence of innumerable cysts on chest CT imaging combined with renal AMLs was highly suggestive of LAM; the presence of skin findings described above confirmed that this patient had TSC-associated LAM rather than isolated LAM. In this patient, it was also important to recognize LAM before a second renal surgery for AMLs, because a mechanical ventilator strategy that is attentive to avoiding lung hyperinflation is important in patients with cystic lung disease (risk of pneumothorax due to barotrauma) [12]. She had mild airflow obstruction and moderate air trapping on pulmonary function tests with deterioration 5 months later (Table 1). Recent evidence indicates that rapamycin may be useful in TSC for improvement in lung function of patients with LAM and for reduction of renal AML size [17, 18, 2328]. Therefore, in an attempt to prevent AML regrowth and LAM progression, the patient was treated with low-dose rapamycin. Our results demonstrate that rapamycin $1 \mathrm{mg} /$ day given for 12 months resulted in improvement of pulmonary function and radiological LAM-related cystic lung disease [18, 25]. Thus, after 12 months of rapamycin therapy, $\mathrm{FEV}_{1}$ increased by $270 \mathrm{~mL}$, and FVC increased by $570 \mathrm{~mL}$. It is unlikely that these spirometric responses can be explained by the reversal of airflow obstruction alone, given that the increase in FVC was more than two times the increase in $\mathrm{FEV}_{1}$. The most likely explanation for the observed increase in FVC is the relief of gas trapping, indicated by the reduction in RV that occurred with the use of rapamycin. Thus, this patient who had substantial air trapping at baseline (RV $>120 \%$ of the predicted value) had a reduction in RV after 6 and 12 months of receiving rapamycin. A decrease in the infiltration of smooth-muscle cells, or in lung remodelling, in association with the reduction in cyst volume may have contributed to this response. The presence of an increase in TLC suggests that rapamycin might also affect the elastic recoil of the lung. On the contrary, no effect was observed on the $\mathrm{DL}_{\mathrm{CO}}$. Further supporting a therapeutic benefit, the CT data revealed a reduction of the number and size of the pulmonary cysts after 6 months of receiving rapamycin $[18,25]$. Moreover, AML regrowth did not occur over the 12-month time period. One possible explanation for these findings is that rapamycin treatment produced a direct antiproliferative effect and an indirect antiangiogenic effect (affecting vascular endothelial growth factor D levels) [17, 18, 29-31].

In conclusion, to the best of our knowledge, this is the first case of preservation of renal function despite successive bilateral renal surgery in a TSC patient with pregnancy-related giant AMLs. Our data also demonstrate that treatment with low dose of rapamycin resulted in improvement of pulmonary function and cystic lung disease and may be an option in the treatment of LAM. In addition, low dose of rapamycin could prevent AML regrowth. Larger studies are warranted to further examine the relationship between pregnancy, AML and LAM, and the molecular response to rapamycin inhibition in patients with TSC. 


\section{ACKNOWLEDGMENTS}

This work has been supported in part by grants from the Instituto de Salud Carlos III from Ministerio de Ciencia e Innovación (EC08/00236) and Programa Intensificación Actividad Investigadora (IdiPAZ and Agencia Laín-Entralgo/CM) to R. Peces.

\section{CONFLICT OF INTERESTS}

The authors declare that they have no conflict of interests.

\section{REFERENCES}

[1] P. B. Crino, K. L. Nathanson, and E. P. Henske, "Medical progress: the tuberous sclerosis complex," New England Journal of Medicine, vol. 355, no. 13, pp. 1306-1356, 2006.

[2] R. Mascarenhas and P. McLaughlin, "Haemorrhage from angiomyolipoma of kidney during pregnancy-a diagnostic dilemma," Irish Medical Journal, vol. 94, no. 3, pp. 84-85, 2001.

[3] M. Fernández Arjona, R. Mínguez, P. Serrano et al., "Rapidly-growing renal angiomyolipoma associated with pregnancy," Actas Urologicas Espanolas, vol. 18, no. 7, pp. 755-757, 1994.

[4] J. L. Koh, Y. H. Lee, C. Y. Kang, and C. N. Lin, "Simultaneous cesarean section and radical nephrectomy for angiomyolipoma with spontaneous bleeding during pregnancy: a case report," Journal of Reproductive Medicine for the Obstetrician and Gynecologist, vol. 52, no. 4, pp. 338-340, 2007.

[5] J. Raft, J. -M. Lalot, C. Meistelman, and D. Longrois, "Influence of pregnancy on renal angiomyolipoma," Gynecologie Obstetrique Fertilite, vol. 33, no. 11, pp. 898-906, 2005.

[6] T. I. Molina, J. M. Montes, E. C. Cecilia, M. D. M. M. Muñiz, A. G. González, and M. Á. H. Martínez, "Angiomyolipomas, tuberous sclerosis and pregnancy," Ginecologia y Obstetricia de Mexico, vol. 77, no. 8, pp. 380-386, 2009.

[7] B. E. G. Rothberg, M. C. Grooms, and V. R. Dharnidharka, "Rapid growth of a kidney angiomyolipoma after initiation of oral contraceptive therapy," Obstetrics and Gynecology, vol. 108, no. 3, pp. 734-736, 2006.

[8] S. A. Boorjian, Y. Sheinin, P. L. Crispen, C. M. Lohse, E. D. Kwon, and B. C. Leibovich, "Hormone receptor expression in renal angiomyolipoma: clinicopathologic correlation," Urology, vol. 72, no. 4, pp. 927-932, 2008.

[9] J. A. King and D. M. Stamilio, "Maternal and fetal tuberous sclerosis complicating pregnancy: a case report and overview of the literature," American Journal of Perinatology, vol. 22, no. 2, pp. 103-108, 2005.

[10] A. Al-Ateeqi, R. H. Ali, E. O. Kehinde, K. Mujaibel, A. Al-Hunayan, and J. Al-Harmi, "Increasing severity of haematuria with successive pregnancies in a woman with renal angiomyolipoma," International Urology and Nephrology, vol. 39, no. 2, pp. 409-412, 2007.

[11] M. M. Cohen, A. M. Freyer, and S. R. Johnson, "Pregnancy experiences among women with lymphangioleiomyomatosis," Respiratory Medicine, vol. 103, no. 5, pp. 766-772, 2009.

[12] S. Mitra, A. G. Ghosal, and P. Bhattacharya, "Pregnancy unmasking lymphangioleiomyomatosis," Journal of Association of Physicians of India, vol. 52, pp. 828-830, 2004.

[13] S. S. Gargari, S. Hantoushzadae, F. Mohamadi, and M. Jafar-Abadi, "Pregnancy complicated by Lymphangioleiomyomatosis," Archives of Iranian Medicine, vol. 12, no. 2, pp. 182-185, 2009.

[14] S. Y. Cho, K. H. Kim, and W. J. Jeon, "Caesarean delivery under general anaesthesia for a woman with undiagnosed tuberous sclerosis complex and lymphangioleiomyomatosis," Anaesthesia and Intensive Care, vol. 37, no. 1, pp. 142-143, 2009.

[15] S. Yano, "Exacerbation of pulmonary lymphangioleiomyomatosis by exogenous oestrogen used for infertility treatment," Thorax, vol. 57, no. 12, pp. 1085-1086, 2002.

[16] V. Gimeno Argente, M. Bosquet Sanz, M. A. Bonillo García, L. Gómez Pérez, J. L. Pontones Moreno, and J. F. Jiménez Cruz, "Conservative surgery of bilateral renal angiomyolipoma during pregnancy," Actas Urologicas Espanolas, vol. 30, no. 6, pp. 633-637, 2006. 
[17] L. R. Young, Y. Inoue, and F. X. McCormack, "Diagnostic potential of serum VEGF-D for lymphangioleiomyomatosis," New England Journal of Medicine, vol. 358, no. 2, pp. 199-200, 2008.

[18] F. X. McCormack, Y. Inoue, J. Moss et al., "Efficacy and safety of sirolimus in lymphangioleiomyomatosis," New England Journal of Medicine, vol. 364, no. 17, pp. 1595-1606, 2011.

[19] F. G. Vianna, E. Marchiori, G. Zanetti et al., "Tuberous sclerosis with pulmonary lymphangioleiomyomatosis and renal angiomyolipomas. Computed tomographic findings: a case report," Cases Journal, vol. 2, no. 12, article no. 9124, 2009.

[20] S. Yoshida, T. Hayashi, N. Ishii et al., "Bilateral renal angiomyolipoma coexistent with pulmonary lymphangioleiomyomatosis and tuberous sclerosis," International Urology and Nephrology, vol. 38, no. 3-4, pp. 413-415, 2006.

[21] E. Tüzel, Z. Kirkali, U. Mungan, C. Cüler, and M. Sade, "Giant angiomyolipoma associated with marked pulmonary lesions suggesting lymphangioleiomyomatosis in a patient with tuberous sclerosis," International Urology and Nephrology, vol. 32, no. 2, pp. 219-222, 2000.

[22] J. J. Yu, V. A. Robb, T. A. Morrison et al., "Estrogen promotes the survival and pulmonary metastasis of tuberinnull cells," Proceedings of the National Academy of Sciences of the United States of America, vol. 106, no. 8, pp. 2635-2640, 2009.

[23] J. M. Morton, C. McLean, S. S. Booth, G. I. Snell, and H. M. Whitford, "Regression of pulmonary lymphangioleiomyomatosis (PLAM)-associated retroperitoneal angiomyolipoma post-lung transplantation with rapamycin treatment," Journal of Heart and Lung Transplantation, vol. 27, no. 4, pp. 462-465, 2008.

[24] J. J. Bissler, F. X. McCormack, L. R. Young et al., "Sirolimus for angiomyolipoma in tuberous sclerosis complex or lymphangioleiomyomatosis," New England Journal of Medicine, vol. 358, no. 2, pp. 140-151, 2008.

[25] D. M. Davies, S. R. Johnson, A. E. Tattersfield et al., "Sirolimus therapy in tuberous sclerosis or sporadic lymphangioleiomyomatosis," New England Journal of Medicine, vol. 358, no. 2, pp. 200-203, 2008.

[26] E. Paul and E. Thiele, "Efficacy of sirolimus in treating tuberous sclerosis and lymphangioleiomyomatosis," New England Journal of Medicine, vol. 358, no. 2, pp. 190-192, 2008.

[27] J. J. Egan, K. F. Remund, and P. Corris, “Sirolimus for lymphangioleiomyomatosis lesions,” New England Journal of Medicine, vol. 358, no. 18, pp. 1963-1964, 2008.

[28] R. Peces, C. Peces, E. Cuesta-López et al., "Low-dose rapamycin reduces kidney volume angiomyolipomas and prevents the loss of renal function in a patient with tuberous sclerosis complex," Nephrology, Dialysis, Transplantation, vol. 25, no. 11, pp. 3787-3791, 2010.

[29] D. M. Davies, P. J. De Vries, S. R. Johnson et al., "Sirolimus therapy for angiomyolipoma in tuberous sclerosis and sporadic lymphangioleiomyomatosis: a phase 2 trial," Clinical Cancer Research, vol. 17, no. 12, pp. 40714081, 2011.

[30] A. M. Taveira-Dasilva, O. Hathaway, M. Stylianou, and J. Moss, "Changes in lung function and chylous effusions in patients with lymphangioleiomyomatosis treated with sirolimus," Annals of Internal Medicine, vol. 154, no. 12, pp. 797-805, 2011.

[31] A. P. Lam, T. C. Corbridge, D. Batlle, V. Torres, C. Quijano, and A. Serrano, "Multiple cysts in the kidney and lungs in a patient with polycystic kidney disease and lymphangioleiomyomatosis," TheScientificWorldJournal, vol. 7, pp. 80-82, 2007.

\section{This article should be cited as follows:}

Ramón Peces, Emilio Cuesta-López, Carlos Peces, and Rafael Selgas, "Giant Bilateral Renal Angiomyolipomas and Lymphangioleiomyomatosis Presenting after Two Successive Pregnancies Successfully Treated with Surgery and Rapamycin,” TheScientificWorldJOURNAL, vol. 11, pp. 2115-2123, 2011. 


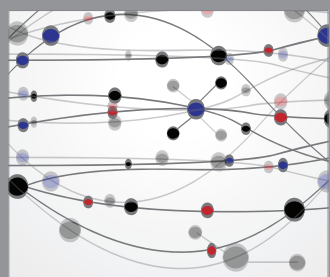

The Scientific World Journal
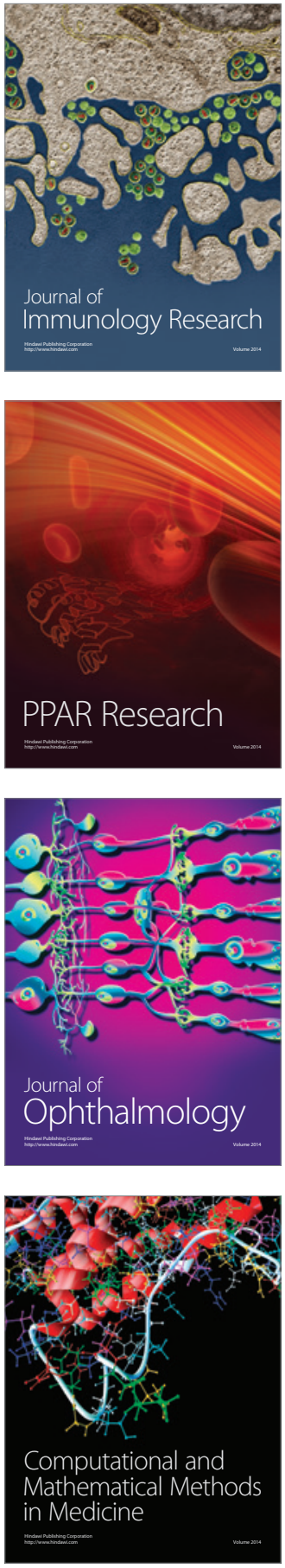

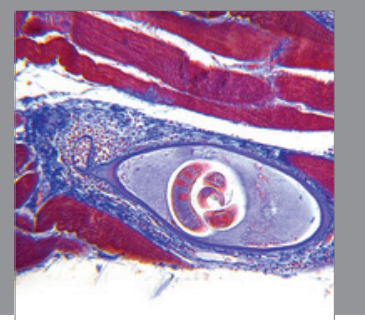

Gastroenterology

Research and Practice
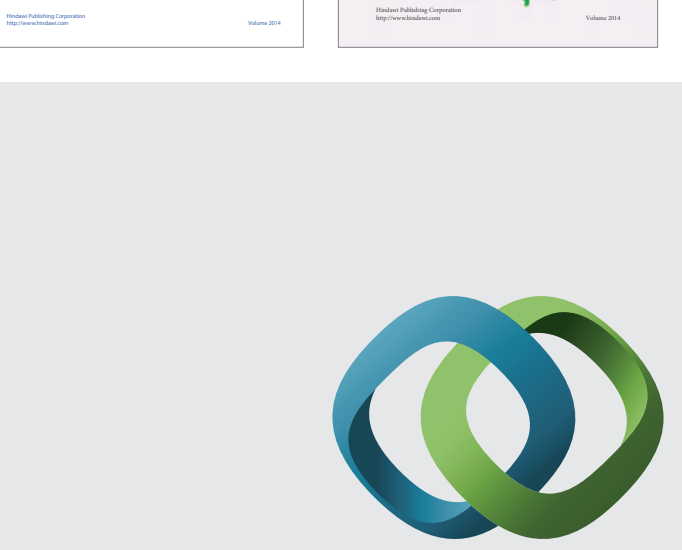

\section{Hindawi}

Submit your manuscripts at

http://www.hindawi.com
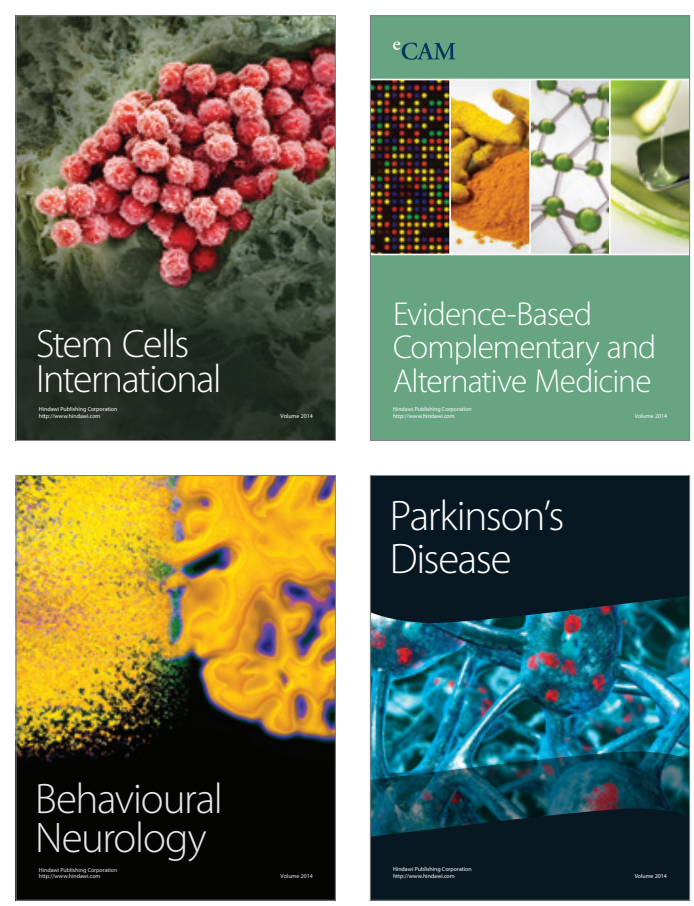

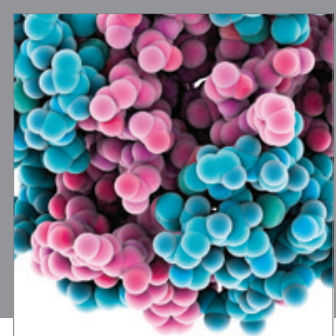

Journal of
Diabetes Research

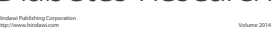

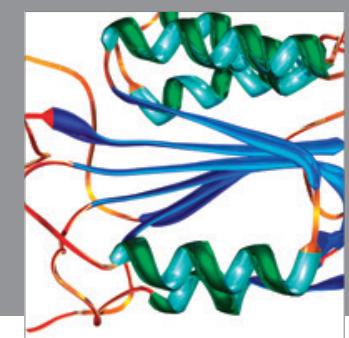

Disease Markers
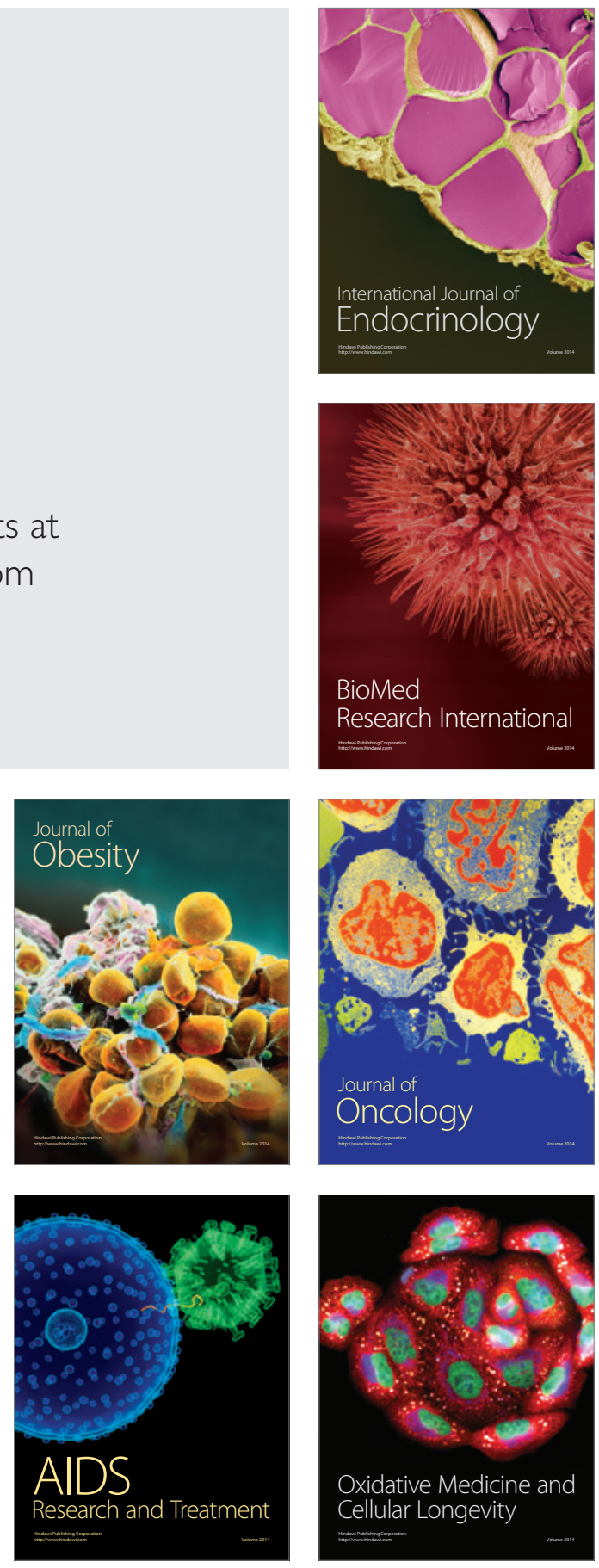